\title{
UPORABA METODE ELEKTRIČNE UPORNOSTI TAL NA PRIMERU DIVAŠKE JAME
}

\author{
dr. Andrej Mihevc*, dr. Uroš Stepišnik ${ }^{* *}$ \\ *Inštitut za raziskovanje krasa ZRC SAZU \\ Titov trg 2, SI-6230 Postojna \\ e-mail: mihevc@zrc-sazu.si \\ ** Oddelek za geografijo, Filozofska fakulteta Univerze v Ljubljani \\ Aškerčeva 2, SI-I000 Ljubljana \\ e-mail: uros.stepisnik@gmail.com \\ Izvirni znanstveni članek \\ COBISS 1.01
}

\section{Izvleček}

Električna upornost tal je geofizikalna metoda, s katero se ugotavlja struktura tal pod površjem. Za preizkus uporabnosti metode so bili izdelani profili nad jamo Trhlovca in Divaško jamo ter njenim nadaljevanjem v brezstropi jami na pobočju Radvanja na Divaškem krasu. Rezultati kažejo, da votlih jamskih prostorov zaradi velike električne upornosti matične kamnine ni mogoče zaznati, lahko pa zaznamo jarke brezstropih jam in podzemne jame, ki so zapolnjene z ilovnatim sedimentom.

Ključne besede: Slovenija, kras, jama, denudirana jama, električna upornost tal

\section{APPLICATION OF ELECTRICAL RESISTIVITY IMAGING ON DIVAŠKA JAMA CAVE}

\begin{abstract}
Electrical resistivity imaging (ERI) is a widely used tool in geophysical survey of various subsurface structures. To establish its applicability for karst subsurface, ERI was conducted in Divača karst above caves of Trhlovca and Divaška jama and in its continuation as denuded cave on slopes of Radvanj collapse doline. Empty cave passages were not detected with ERI as electrical resistivity difference between voids and highly resistive carbonate bedrock is too small. On the other hand, denuded caves and cave sections, filled with loamy material, can be clearly distinguished.
\end{abstract}

Key words: Slovenia, karst, cave, denuded cave, electrical resistivity imaging (ERI) 


\section{UVOD}

V članku je opisana uporaba geofizikalne metode električne upornosti tal za zaznavanje jam pod površjem. Glavni namen raziskave je bil preizkus uporabnosti te metode za zaznavanje praznih jamskih prostorov v krasu.

Preučevano območje se nahaja v skrajnem jugovzhodnem delu planote Kras jugozahodno od Divače. Metoda je bila preizkušena na primerih poznanih delov jame Trhlovce in Divaške jame ter brezstrope jame vzhodno od Divaške jame.

Za merjenje električne upornosti tal je bil uporabljen SuperSting R1/IP, ki ga je razvil Advanced Geosciences, Inc. Pridobljene podatke o električni upornosti tal smo obdelali s programom EarthImager 2D inversion software. Metoda električne upornosti tal se je v preteklosti že izkazala kot primerna za ugotavljanje podzemne zgradbe epikrasa, predvsem vrtač in udornic (Stepišnik, Mihevc, 2008; Stepišnik, 2009).

Dosedanje raziskave so pokazale, da je metoda uporabna za prepoznavanje podzemnih struktur, kjer so velike razlike v električni upornosti. Izredno uporabna je za ugotavljanje globine in oblike ilovnatih zapolnitev v apnenčastem površju, kakršne so v udornicah, vrtačah in brezstropih jamah, saj ima ilovnat sediment nizko, karbonatna matična kamnina pa visoko električno upornost. Pri praznih, nezapolnjenih jamskih prostorih pa je električna upornost teoretično neskončna, okoliška karbonatna kamnina pa ima visoko upornost.

\section{OSNOVNE ZNAČILNOSTI DIVAŠKEGA KRASA}

Kras je apnenčasta planota, ki se nahaja nad Tržaškim zalivom v zahodni Sloveniji. Razpotegnjena je v dinarski smeri, dolga okoli $40 \mathrm{~km}$ in široka do $14 \mathrm{~km}$; površina Krasa znaša $440 \mathrm{~km}^{2}$. Divaški kras se nahaja v jugovzhodnem delu Krasa, med ponori Reke v Škocjanskih jamah in Divačo (slika 1). Na območju prevladujejo kredni apnenci s povprečnim vpadom skladov $20^{\circ}$ proti jugu. Na jugu preidejo $\mathrm{v}$ paleogenske tanko plastovite apnence (Jurkovšek in sod., 1996).

V jugovzhodnem delu Divaškega krasa Reka ponikne v 5800 m dolge Škocjanske jame na nadmorski višini 317 m, končni sifon Škocjanskih jam pa se nahaja na nadmorski višini 190 m. Okoli 900 m za končnim sifonom je 12.700 m dolga Kačna jama, skozi katero odteka Reka proti zahodu v smeri izvirov Timave.

Površje Divaškega krasa je v grobem uravnano na nadmorski višini $430 \mathrm{~m}$ in razjedeno s številnimi vrtačami, udornicami in brezstropimi jamami. Vrtače imajo premer od 50 do $100 \mathrm{~m}$ in so v povprečju okoli $10 \mathrm{~m}$ globoke. Gostota vrtač je na nekaterih delih višja od 200 na kvadratni kilometer. Njihove prostornine znašajo od nekaj tisoč do deset tisoč kubičnih metrov (Mihevc, 1997). Na površju je tudi 27 večjih udornic, ki imajo skupno prostornino več kot $41 \mathrm{mil}^{3}$; njihova povprečna globina je $45 \mathrm{~m}$, povprečen premer pa $135 \mathrm{~m}$. Na uravnanem površju Divaškega krasa je tudi več brezstropih jam, ki so večinoma denudirani rovi horizontalnih epifreatičnih jam. Najdaljši odsek brezstrope jame je okoli 30 m širok in dolg več kot 600 m (Mihevc, 1997). 
Slika 1: Lega preučevanega območja

Figure 1: Location of the study area

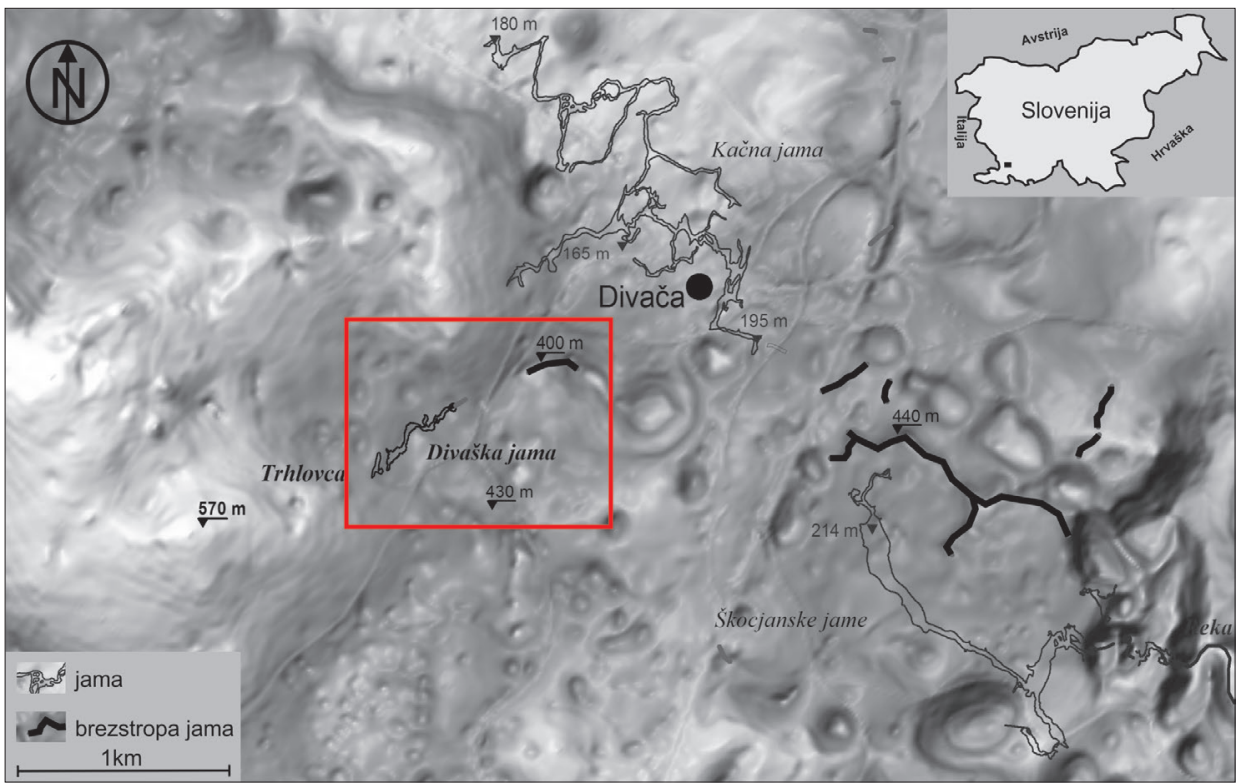

\section{SPELEOLOŠKE IN GEOMORFOLOŠKE ZNAČILNOSTI PREUČEVANEGA OBMOČJA}

Vzhodni del preučevanega območja okrog Divaške jame (slika 1) se postopoma znižuje v podolgovato globel denudirane jame, ta pa se na vzhodnem koncu nadaljuje v udornico Divaški Radvanj. Na preučevanem območju sta znani dve večji jami: daljša je Divaška jama, ki poteka v smeri severovzhod-jugozahod na nadmorskih višinah med 350 in $410 \mathrm{~m}$. Druga manjša jama Trhlovca se nahaja zahodno od Divaške jame.

Divaška jama se je razvila v plastovitem senonskem apnencu (Jurkovšek in sod., 1996). Plasti apnenca v jami vpadajo proti jugozahodu in jugu (Gospodarič, 1985). Jama predstavlja okoli $700 \mathrm{~m}$ dolg odsek epifreatičnega, delno tudi freatičnega jamskega sistema. Največji rovi so do $20 \mathrm{~m}$ visoki in $15 \mathrm{~m}$ široki. Jamske rove zapolnjuje vsaj $30 \mathrm{~m}$ alogenih ilovnatih sedimentov in sig različne starosti. Edino znano podzemno nadaljevanje Divaške jame je jama Trhlovca, a jami nista neposredno povezani.

Trhlovca je $142 \mathrm{~m}$ dolga in $22 \mathrm{~m}$ globoka jama. Njen osrednji del je okoli $15 \mathrm{~m}$ visok, 3 $\mathrm{m}$ širok in $60 \mathrm{~m}$ dolg meander, ki poteka v smeri sever-jug na nadmorski višini od 404 do 419 m. Jama je nastala $v$ freatičnih in epifreatičnih pogojih (Zupan Hajna in sod., 2008).

Na vzhodu se preučevano območje zaključi z udornico Radvanj, sestavljeno iz dveh delov: Divaškega Radvanja in Gorenjskega Radvanja. Pobočja Gorenjskega Radvanja 
so pretežno uravnotežena, spodnje dele pobočij in dno zapolnjuje ilovnat sediment. Na zahodnem pobočju sta na večji zaplati ilovnatega sedimenta dva erozijska jarka.

\section{UPORABA METODE ELEKTRIČNE UPORNOSTI TAL}

Podatki o električni upornosti tal so bili pridobljeni v osmih profilih nad Divaško jamo in njenim domnevnim nadaljevanjem ter brezstropo jamo nad obodom udornice Radvanj. Električna upornost tal je bila izmerjena s SuperSting R1/IP merilcem električne upornosti. Meritve so potekale po metodi dipole-dipole in s 5-metrsko razdaljo med posameznimi elektrodami. Podatke električne upornosti tal smo obdelali s programom EarthImager 2D resistivity inversion software. Lokacije vseh izdelanih profilov električne upornosti tal so prikazane na sliki 2.

Predhodna merjenja s to metodo v različnih kraških okoljih v Sloveniji so pokazala, da so vrednosti električne upornosti tal za karbonatne kamnine večje od 1000 ohm-m, za prst in preperelo karbonatno kamnino med 20 in $1000 \mathrm{ohm}-\mathrm{m}$, ilovnat sediment pa ima upornost manjšo od 150 ohm-m (Stepišnik, 2007; Stepišnik, Mihevc, 2008; Stepišnik, 2009). Kljub številnim meritvam doslej niso bile določene vrednosti električne upornosti, ki bi pokazale razliko med karbonatno kamnino in jamskimi votlinami. Ker imajo prazni jamski prostori skoraj neskončno električno upornost, okoliška matična kamnina pa zelo visoke vrednosti upornosti, so bile v okviru te raziskave opravljene podrobne meritve z namenom, da bi zaznali te razlike, oziroma nezapolnjene jamske prostore.

Slika 2: Lokacije profilov električne upornosti tal z globinami

Figure 2: Location of ERI profiles with depths

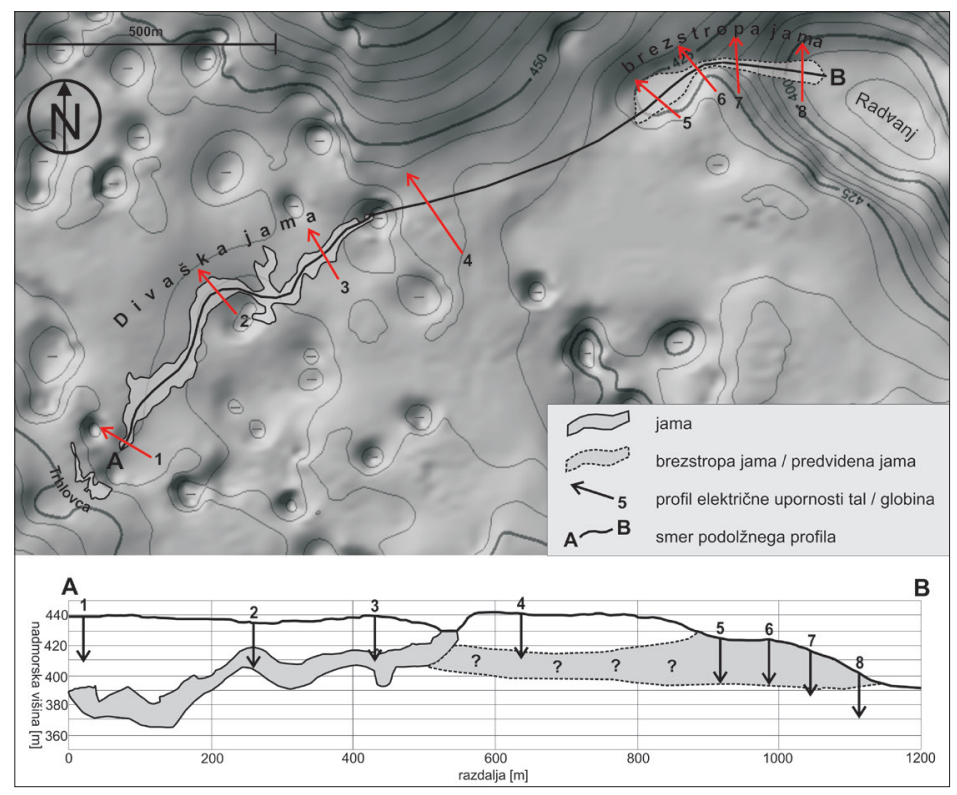


Profili električne upornosti tal prek Trhlovce in Divaške jame (profili 1, 2, 3) kažejo relativno homogeno strukturo, ki je rezultat visoke električne upornosti karbonatne kamnine in praznih jamskih prostorov (slika 3). Prvi profil je bil izmerjen prek jugozahodnega zaključka Divaške jame v smeri $290^{\circ}$. Karbonatna matična kamnina z električno upornostjo nad $1000 \mathrm{ohm}-\mathrm{m}$ je prekrita s plitvo prstjo in razpadlo matično kamnino, ki ima električno upornost manjšo od $500 \mathrm{ohm}-\mathrm{m}$. V osrednjem delu profila na globini okoli 25 m je območje z električno upornostjo pod 150 ohm-m, ki je morda z ilovico zapolnjeno nadaljevanje Divaške jame v smeri Trhlovce. Znani rovi Divaške jame se v tem delu nahajajo $50 \mathrm{~m}$ pod površjem in jih metoda električne upornosti ni zaznala, saj je maksimalna globina tega profila le 28 metrov.

Slika 3: Profili električne upornosti tal št. 1, 2, 3 in 4

Figure 3: ERI profiles number 1, 2, 3 and 4

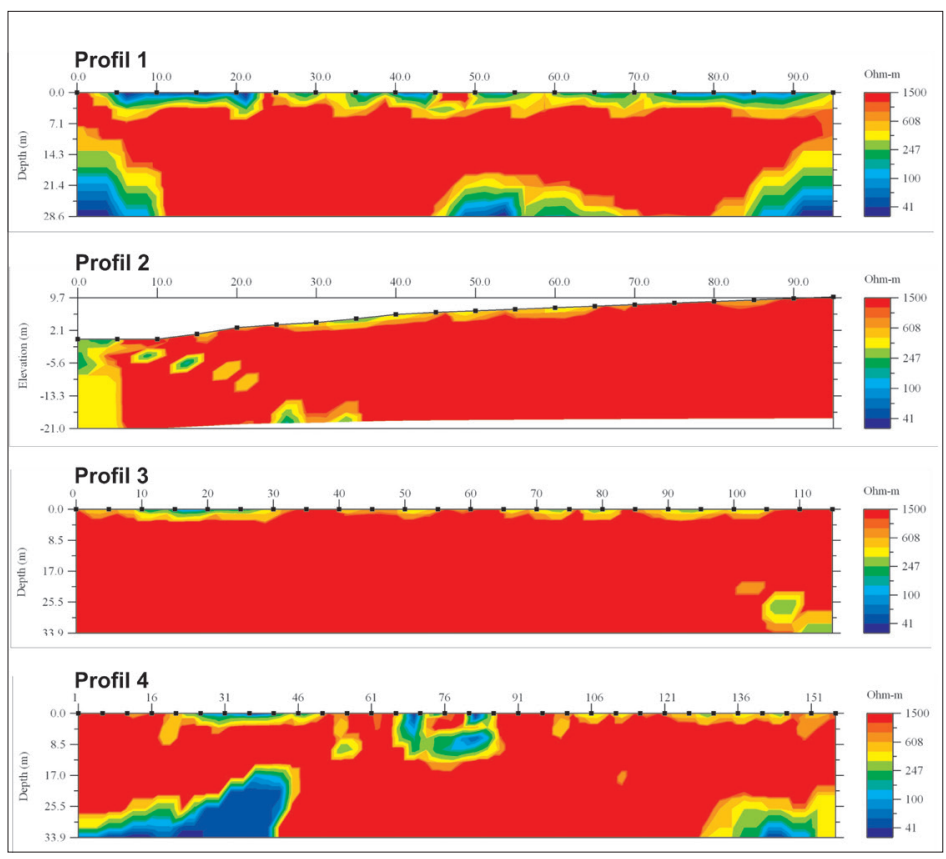

Profil št. 2 se nahaja nad delom Divaške jame, ki leži le 15 m pod površjem. Profil poteka v smeri $300^{\circ}$ prek severozahodnega pobočja vrtače. Karbonatna matična podlaga z električno upornostjo nad 1000 ohm-m je prekrita s tanko plastjo električno manj odporne prsti in preperele kamnine. V osrednjem delu profila, na globini okoli $15 \mathrm{~m}$, se nahaja rov Divaške jame. Rov bi moral izkazovati veliko večjo električno upornost od okoliške kamnine, a je električna upornost $\mathrm{v}$ tem delu enakomerna; torej rova s to metodo nismo zaznali.

Ker je bil namen raziskave predvsem preizkus uporabnosti metode električne upornosti tal za odkrivanje jamskih prostorov, so bile na profilu št. 2 uporabljene tudi višje vrednosti 
električne upornosti, ki bi lažje pokazale razlike med karbonatno matično kamnino z visoko električno upornostjo ter praznimi prostori z neskončno električno upornostjo (slika 4). Uporabljene so bile vrednosti od 1000 do 5000 ohm-m, od 3000 do 10.000 ohm-m, od 8000 do 15.000 ohm-m in od 10.000 do 20.000 ohm-m. Pri nobenem razponu vrednosti nismo zaznali jamskega rova, jasno pa se vidi električna upornost epikraške cone (profil št. 2, razpon električne upornosti od 3000 do 10.000 ohm-m), ki znaša od 1000 do 3000 ohm-m. Pri višjih vrednostih upornosti lahko tudi razberemo, da je bila upornost matične kamnine (plastovit senonski apnenec) v merjenih pogojih med 3000 in 7000 ohm-m.

Slika 4: Profil št. 2 z različnimi vrednostmi električne upornosti

Figure 4: ERI profile 2 with different resistivity values

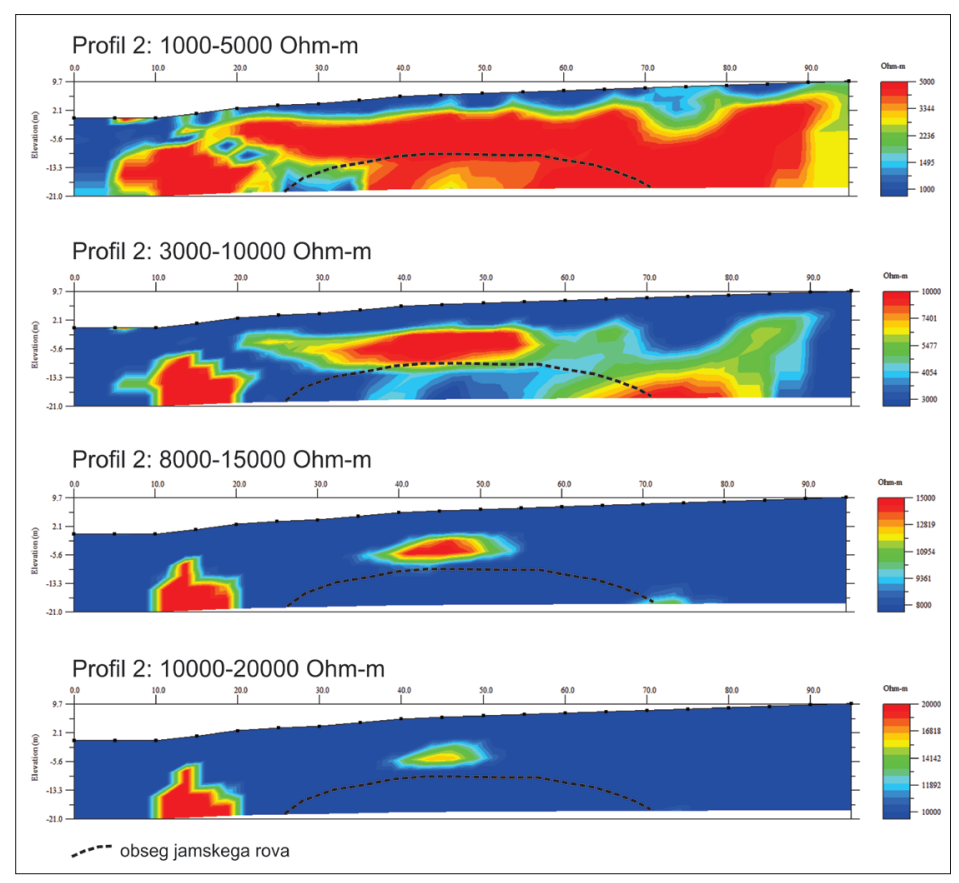

Profil št. 3 poteka prek severovzhodnega dela Divaške jame, ki se v tem delu nahaja $22 \mathrm{~m}$ pod površjem (slika 3). Profil poteka po ravnem kraškem površju v smeri $305^{\circ}$. Karbonatna matična kamnina z električno upornostjo tal nad 1000 ohm-m je prekrita S plitvo prstjo in razpadlo matično kamnino, ki ima vrednosti električne upornosti manjše od 500 ohm-m. V osrednjem delu profila se pod površjem nahajajo rovi Divaške jame, a niso bili zaznani, saj izkazujejo enako električno upornost kot okoliška kamnina.

Profil št. 4 je bil izdelan na uravnanem kraškem površju med severovzhodnim zaključkom Divaške jame in njenim domnevnim nadaljevanjem v smeri brezstrope jame nad udornico Gorenjski Radvanj (slika 3). V območju profila, ki poteka v smeri 300 , ni znanih jam. Karbonatna matična kamnina z električno upornostjo tal nad 1000 ohm-m je prekrita s plitvo 
prstjo in razpadlo matično kamnino, ki ima vrednosti električne upornosti manjše od 500 $\mathrm{ohm}-\mathrm{m}$. V osrednjem delu profila je med površjem in globino okoli $10 \mathrm{~m}$ podzemna oblika z vrednostmi električne upornosti okoli $500 \mathrm{ohm}-\mathrm{m}$. Najverjetneje gre za epikraško ali vadozno votlino, zapolnjeno z ilovnatim materialom. $\mathrm{V}$ jugovzhodnem delu profila je na globini pod $17 \mathrm{~m}$ podzemna oblika s premerom okoli $30 \mathrm{~m}$. Električna upornost te oblike znaša manj kot $150 \mathrm{ohm}-\mathrm{m}$, zato gre najverjetneje za jamski rov, ki je povsem zapolnjen z ilovnatim sedimentom. Predvidevamo, da je to podzemno nadaljevanje Divaške jame proti severovzhodu.

Profili št. 5, 6, 7 in 8 potekajo prek brezstrope jame, ki je v dnu zapolnjena z ilovnatim sedimentom in kosi sige (slika 5). Profili električne upornosti tal kažejo jasno razliko med jamskimi sedimenti in karbonatno kamnino.

Profil št. 5, ki poteka v smeri $290^{\circ}$, je bil izdelan v jugozahodnem delu brezstrope jame. Matična kamnina v pobočjih brezstrope jame ima električno upornost prek 1000 ohm-m. Prekrita je z električno manj uporno prstjo, preperelo kamnino in ilovnatim materialom z električno upornostjo okoli $500 \mathrm{ohm}-\mathrm{m}$. Vsi ostali deli profila, predvsem osrednji, imajo električno upornost manjšo od 150 ohm-m, kar ustreza vrednostim za ilovnat sediment, ki zapolnjuje dno brezstrope jame. Globina ilovnatega sedimenta v brezstropi jami presega $20 \mathrm{~m}$, torej je nastala iz obsežnih jamskih prostorov. Na globini okoli $10 \mathrm{~m}$ je v ilovnatem sedimentu okoli $10 \mathrm{~m}$ debela struktura z električno upornostjo okoli 500 ohm-m, ki je najverjetneje pobočni grušč, sedimentiran med ilovico.

Slika 5: Profili električne upornosti tal št. 5, 6, 7 in 8

Figure 5: ERI profiles number 5, 6, 7 and 8

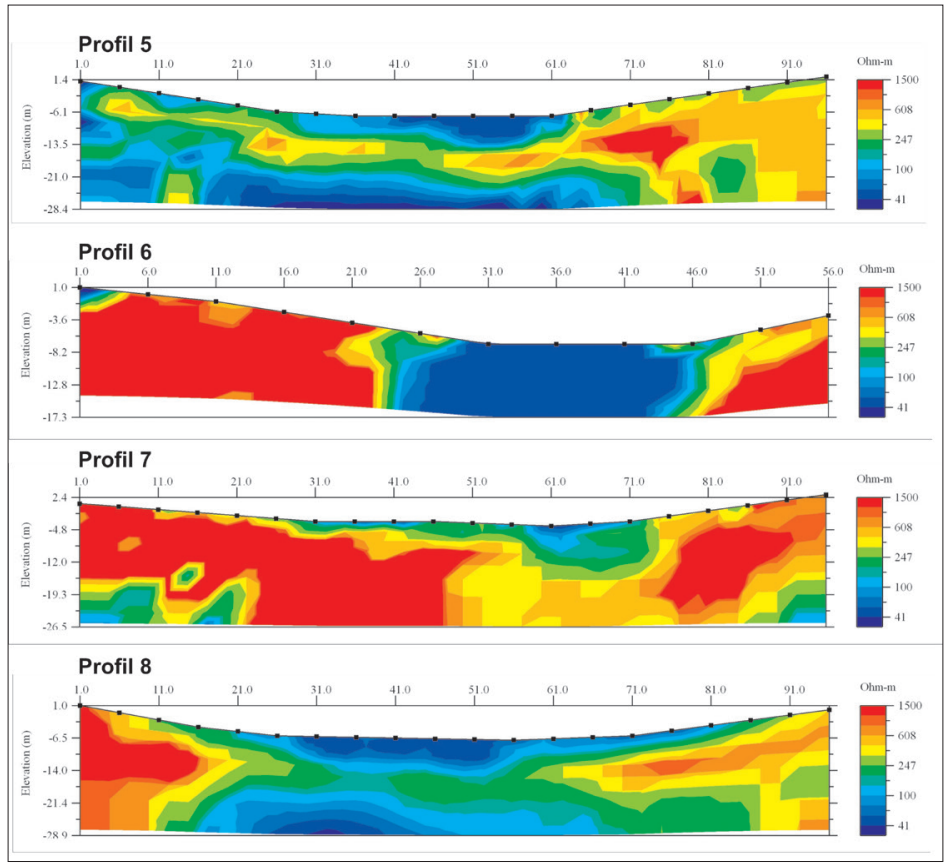


Profil št. 6 se nahaja v severovzhodnem delu brezstrope jame, na obodu udornice Gorenjski Radvanj, in poteka v smeri $290^{\circ}$. Na obeh pobočjih brezstrope jame se nahaja matična kamnina z električno upornostjo večjo od 1000 ohm-m. V osrednjem delu brezstrope jame je ilovnat material s kosi sige, ki ima električno upornost manjšo od 150 ohm-m in dosega globino prek $15 \mathrm{~m}$.

$\mathrm{V}$ osrednjem delu profila št. 7, ki poteka po zahodnem pobočju udornice Radvanj v smeri $350^{\circ}$, se nahaja ilovnat material z električno upornostjo manjšo od $150 \mathrm{ohm}-\mathrm{m}$. Globina ilovnate zapolnitve je $10 \mathrm{~m}$, širina pa okoli $15 \mathrm{~m}$. Pod ilovnatim sedimentom in v njegovi okolici se nahaja matična kamnina z električno upornostjo nad 1000 ohm-m.

Profil št. 8 poteka po zahodnem pobočju udornice Radvanj, kamor se izteče rov brezstrope jame. Na obeh koncih profila, kjer dno udornice prehaja v pobočje, se nahaja matična kamnina z električno upornostjo 1000 ohm-m. V zgornjem delu je na sredini profila ilovnat material s kosi sige, ki ima električno upornost manj kot 150 ohm-m. Ta ilovnat material je bil spran po pobočju iz brezstrope jame. Pod ilovico je na globini okoli 10 m struktura z električno upornostjo med 200 in 500 ohm-m, ki je najverjetneje pobočni grušč. Pod njim je ponovno ilovnat material z električno upornostjo manj kot $150 \mathrm{ohm}-\mathrm{m}$. Ta ilovnat sediment zapolnjuje celotno dno udornice in najverjetneje ni $\mathrm{v}$ genetski povezavi s sedimenti iz brezstrope jame (Stepišnik, 2009).

\section{SKLEP}

Profili električne upornosti tal so bili izmerjeni na osmih lokacijah nad jamo Trhlovco, Divaško jamo in njenim brezstropim nadaljevanjem nad in v pobočju udornice Radvanj.

Profili električne upornosti tal nad Divaško jamo (1, 2, in 3) kažejo dokaj enotno zgradbo, kar je rezultat visoke električne upornosti karbonatne matične kamnine ter rovov. Čeprav so jamski prostori relativno blizu površja, jih uporabljena metoda ni zaznala. Na profilu št. 2, kjer se večji jamski rov nahaja najbližje površju, smo uporabili veliko večje vrednosti električne upornosti, a vseeno nismo mogli zaznati praznih podzemskih votlin.

Profil št. 4, ki je bil izmerjen prek območja domnevnega nadaljevanja Divaške jame v smeri brezstrope jame nad Radvanjem, je potrdil obstoj jamskega rova. Rov je zapolnjen z električno manj upornim ilovnatim materialom in ga je bilo mogoče zaznati.

Brezstropa jama je povsem zapolnjena z ilovnatim sedimentom in kosi sige, kar je metoda jasno zaznala v profilih št. 5, 6, 7 in 8 . V brezstropi jami nad obodom udornice Radvanj, kjer je brezstropa jama široka okoli 20 m, je globina ilovnatih zapolnitev večja od $20 \mathrm{~m}$. Na pobočju udornice je globina ilovnatih zapolnitev veliko manjša, le nekaj metrov, kar je rezultat pobočnega spiranja drobnozrnatega sedimenta. Le v dnu udornice je ponovno več ilovnatega sedimenta, saj se v tem delu poleg pobočnega grušča odlaga tudi spran sediment iz brezstrope jame.

Uporaba metode električne upornosti tal se je v tej raziskavi izkazala pri zaznavanju struktur z veliko razliko v električni upornosti. Z njo je torej mogoče zaznati podzemne dele brezstropih jam in jam, ki so zapolnjene z ilovnatim sedimentom, saj se ta jasno 
razlikuje od bolj uporne matične kamnine. Kljub uporabi različnih vrednosti upornosti pa ni bilo mogoče zaznati praznih jamskih prostorov, saj je razlika v električni upornosti premajhna, da bi jo bilo mogoče zaznati.

\section{Viri in literatura}

Gospodarič, R., 1985. O speleogenezi Divaške jame in Trhlovce. Acta carsologica, 13, 1, str. 5-34. Ljubljana.

Jurkovšek, B., Toman, M., Ogorelec, B., Šribar, L., Drobne, K., Poljak, M., Šribar, L., 1996. Formacijska geološka karta južnega dela Tržaško-komenske planote. Ljubljana, Inštitut za geologijo, geotehniko in geofiziko, 143 str.

Mihevc, A., 1997. Dolines, their morphology and origin. Case study: dolines from the Kras, west Slovenia (the Skocjan karst). V: Fourth International Conference on Geomorphology - Italy 1997. Milano, The International Association of Geomorphologists, str. 69-74.

Stepišnik, U., 2007. Loamy sediment fills in collapse dolines near the Ljubljanica River springs, Dinaric Karst, Slovenia. Cave and karst science, 33, 1, str. 23-32. London.

Stepišnik, U., 2009. The application of electrical resistivity imaging in collapse doline floors: Divača karst, Slovenia. Studia geomorphologica Carpatho-Balcanica, 42, str. 41-56. Kraków.

Stepišnik, U., Mihevc, A., 2008. Investigation of structure of various surface karst formations in limestone and dolomite bedrock with application of the electrical resistivity imaging. Acta carsologica, 37, 1, str. 133-140. Ljubljana.

Zupan Hajna, N., Mihevc, A., Pruner, P., Bosák, P., 2008. Paleomagnetism and magnetostratigraphy of karst sediments in Slovenia. Ljubljana, Založba ZRC, 266 str.

\section{APPLICATION OF ELECTRICAL RESISTIVITY IMAGING ON DIVAŠKA JAMA CAVE}

\section{Summary}

Electrical resistivity imaging (ERI) data were collected along eight profiles above caves of Divaška jama and Trhlovca and across their denuded continuation on the slope of Radvanj collapse doline.

The ERI profiles across caves Divaška jama and Trhlovca (profiles 1,2 and 3) exhibit relatively uniform subsurface structure which is a result of high electrical resistivity of limestone bedrock and cave voids. Although the cave passages are relatively close to the surface, they were not detected with the application of ERI even at higher resistivity values which should show the difference between bedrock and void.

The ERI profiles across presumable underground continuation of Divaška jama (profile 4) in direction of the unroofed cave show some differences in subsurface electrical resistivity in depth around $15 \mathrm{~m}$ which may indicate the existence of a cave section completely filled with less resistive loamy material. 
The denuded section of the cave is completely filled with loamy material and flowstone. Results of ERI (profiles 4, 5, 6 and 7) exhibit clear difference between alogenic cave fill and bedrock. In the upper section above the slopes of the Radvanj collapse doline where denuded cave is up to $20 \mathrm{~m}$ wide, the loamy fill is $15 \mathrm{~m}$ thick. On the slopes, the thickness of loamy fill diminishes most likely due to the surface wash. The ERI profile in the lower section of the slope exhibits up to $25 \mathrm{~m}$ of loamy material fill.

Application of the ERI method has been proven appropriate for detailed investigation of subsurface structure with high difference of electrical resistivity. Parts of denuded caves and caves, which are filled with loamy material, can be clearly distinguished from more resistive carbonate bedrock. In the measured ERI profiles, resistivity values of soil and sediment-filled features are lower than $150 \mathrm{ohm}-\mathrm{m}$, weathered bedrock around 500 ohm-m while bedrock exhibits values higher than $1000 \mathrm{ohm}-\mathrm{m}$.

On the other hand, parts of the caves with large passages were not detected in this survey by ERI method as resistivity differences between voids and highly resistive carbonate bedrock are insignificant. 